\title{
Unexpected excessive apixaban exposure: case report of a patient with polymorphisms of multiple apixaban elimination pathways
}

Andrea Huppertz ${ }^{1}$, Caspar Grond-Ginsbach ${ }^{2,3}$, Chris Dumschat ${ }^{2}$, Kathrin I. Foerster ${ }^{1}$, Jürgen Burhenne', Johanna Weiss' ${ }^{1}$ David Czock ${ }^{1}$, Jan C. Purrucker ${ }^{2}$, Timolaos Rizos ${ }^{2 *}$ (D) and Walter E. Haefeli ${ }^{1+}$

\begin{abstract}
Background: Apixaban effectively lowers the risk of ischemic stroke and systemic embolism in patients with nonvalvular atrial fibrillation. Systemic exposure to a given apixaban dose depends on multiple clearance pathways. Though routine quantification of direct oral anticoagulants (DOACs) in neurological emergency situations has not been widely established, suspected associations of DOAC peak concentrations with bleeding events and DOAC trough concentrations with efficacy and safety suggest that such information might support clinical decision making.

Case presentation: We describe the case of a 75 year-old woman with atrial fibrillation maintained on apixaban who was admitted due to suspected acute stroke. Clinical work-up did not confirm ischemic or hemorrhagic stroke but routine quantification of apixaban revealed an excessively high apixaban plasma concentration $(\sim 3 \mathrm{~h}$ after the last drug intake: $1100 \mathrm{ng} / \mathrm{ml}$ (expected range: $91-321 \mathrm{ng} / \mathrm{ml}) ; \sim 12 \mathrm{~h}$ after drug intake: $900 \mathrm{ng} / \mathrm{ml}$ (expected range: $41-230 \mathrm{ng} / \mathrm{ml}))$ and a substantially prolonged elimination half-life $(\sim 31 \mathrm{~h})$. The corresponding apixaban concentrationto-dose ratio was $9900(\mathrm{ng} / \mathrm{ml}) /(\mathrm{mg} / \mathrm{kg} / \mathrm{d})$ and $8100(\mathrm{ng} / \mathrm{ml}) /(\mathrm{mg} / \mathrm{kg} / \mathrm{d})$, respectively (expected range: $249-463(\mathrm{ng} / \mathrm{ml}) /$ $(\mathrm{mg} / \mathrm{kg} / \mathrm{d})$ ). Renal function was only moderately impaired (creatinine $1.36 \mathrm{mg} / \mathrm{dl}(0.5-1.1 \mathrm{mg} / \mathrm{dl})$, creatinine clearance $40 \mathrm{ml} / \mathrm{min}$ ). Genotype analyses revealed that the patient was a CYP3A5*3/*3 non-expressor, a heterozygous carrier of the $A B C G 2$ c.421C/A alleles, and a homozygous carrier of $A B C B 1$ c.2677T/T and ABCB1 c.3435 T/T. In the absence of known drug interactions explaining apixaban clearance impairment, excessive apixaban concentrations were most probably caused by moderate renal impairment combined with multiple functional polymorphisms of apixaban clearance pathways.
\end{abstract}

Conclusions: This case suggests that concurrent genetic polymorphisms can impair multiple apixaban elimination pathways and thus substantially increase its exposure.

Keywords: Direct oral anticoagulants, Apixaban, Plasma concentration, Neurology

\footnotetext{
* Correspondence: timolaos.rizos@med.uni-heidelberg.de

tTimolaos Rizos and Walter E. Haefeli contributed equally to this work.

2Department of Neurology, Heidelberg University Hospital, Im Neuenheimer

Feld 400, 69120 Heidelberg, Germany

Full list of author information is available at the end of the article
}

(c) The Author(s). 2019 Open Access This article is distributed under the terms of the Creative Commons Attribution 4.0 International License (http://creativecommons.org/licenses/by/4.0/), which permits unrestricted use, distribution, and reproduction in any medium, provided you give appropriate credit to the original author(s) and the source, provide a link to the Creative Commons license, and indicate if changes were made. The Creative Commons Public Domain Dedication waiver (http://creativecommons.org/publicdomain/zero/1.0/) applies to the data made available in this article, unless otherwise stated. 


\section{Background}

Apixaban is a rapidly acting, direct concentrationdependent factor $\mathrm{Xa}$ (FXa) inhibitor of both free and prothrombinase-bound FXa [1-3]. It prevents thrombus formation [1-3], thereby considerably lowers the risk of ischemic stroke and systemic embolism in patients with non-valvular atrial fibrillation, and shows a good safety and tolerability profile [4-9]. Systemic apixaban exposure at a given dose depends on multiple clearance pathways involving renal elimination of unchanged drug ( 23\%) $[10,11]$ and oxidative metabolism by cytochrome $\mathrm{P} 450$ (CYP) isozymes, mainly CYP3A4 and polymorphic CYP3A5 ( 20\%) [10, 12] and excretion of unabsorbed apixaban in the gastrointestinal tract (approximately 34\%) [10]. Linear relationships between apixaban concentrations and alteration of coagulation markers have been shown [13], at least for concentrations up to approximately $1000 \mathrm{ng} / \mathrm{ml}$. The bleeding risk associated with very high concentrations remains unclear but is suspected to be considerably increased.

In our institution, quantification of direct oral anticoagulants (DOAC) in neurological emergency situations has been implemented in clinical routine, because their immediate action, the suspected association of peak concentrations with bleeding events [14], and the correlation of trough concentrations with efficacy and safety [15-17] suggest that such information can support clinical decision making.

\section{Case presentation}

In November 2017, a 75-year-old Caucasian woman (body mass index $33 \mathrm{~kg} / \mathrm{m}^{2}$ ) was admitted to our neurological emergency room with suspected acute stroke (weakness of her left leg, fall to the ground where she remained undetected for $12 \mathrm{~h}$ ). She suffered from atrial fibrillation, arterial hypertension, type 2 diabetes mellitus, and hypothyroidism. Her medication comprised apixaban $(2 \times$ $5 \mathrm{mg} / \mathrm{d}$; started in the outpatient setting by the general practitioner in 05/2016), ramipril $10 \mathrm{mg} / \mathrm{d}$, candesartan 8 $\mathrm{mg} / \mathrm{d}$ (CYP2C8 inhibitor), saxagliptin $5 \mathrm{mg} / \mathrm{d}$, levothyroxine $100 \mu \mathrm{g} / \mathrm{d}$ alternating with $125 \mu \mathrm{g} / \mathrm{d}$, and simvastatin $10 \mathrm{mg} / \mathrm{d}$ (CYP3A4 substrate). According to the prescribing list, the medicines taken 'as needed' were: amlodipine (when systolic blood pressure $\geq 160 \mathrm{mmHg}$ ), zopiclone $7.5 \mathrm{mg}$ for insomnia, and pantoprazole $40 \mathrm{mg}$ for ulcer prophylaxis.

The patient was transferred to the stroke unit. Ramipril, candesartan, and apixaban were stopped after admission and apixaban plasma concentrations were quantified using ultra-performance liquid chromatography-tandem mass spectrometry (lower limit of quantification, $1 \mathrm{ng} / \mathrm{ml}$ [18]). At admission, i.e. approximately $3 \mathrm{~h}$ after the last drug intake, the plasma concentration accounted for $1100 \mathrm{ng} /$ $\mathrm{ml}$ (expected range: 91-321 ng/ml [19]). Approximately
$12 \mathrm{~h}$ after drug intake, apixaban plasma concentration remained at high concentrations $(900 \mathrm{ng} / \mathrm{ml}$, expected range: $41-230 \mathrm{ng} / \mathrm{ml}$ [19]), revealing an elimination halflife of approximately $31 \mathrm{~h}$. The corresponding apixaban concentration-to-dose (C/D) ratio was 9900 (ng/ml)/(mg/ $\mathrm{kg} / \mathrm{d}) 3 \mathrm{~h}$ after drug intake and $8100(\mathrm{ng} / \mathrm{ml}) /(\mathrm{mg} / \mathrm{kg} / \mathrm{d})$ at trough (expected range: $249-463(\mathrm{ng} / \mathrm{ml}) /(\mathrm{mg} / \mathrm{kg} / \mathrm{d})$ [20]). The FXa activity was measured by an anti-FXa assay calibrated for apixaban and resulted in somewhat lower but still very high apixaban concentrations (after $3 \mathrm{~h}$ and $12 \mathrm{~h}$ : $900 \mathrm{ng} / \mathrm{ml}$ and $795 \mathrm{ng} / \mathrm{ml}$; Fig. 2). International normalized ratio values were elevated (INR: $1.58,3 \mathrm{~h}$ after drug intake, and 1.45 after $12 \mathrm{~h}$; upper limit of normal: < 1.2 ), whereas and as expected aPTT levels were within normal limits (33.3 and $30.8 \mathrm{~s}$, reference range $<35 \mathrm{~s}$ ) [13, 21]. Other laboratory results at admission revealed rhabdomyolysis (creatine kinase 31,269 U/l (normal < $170 \mathrm{U} / \mathrm{l}$ ), ASAT 863 $\mathrm{U} / \mathrm{l}(<37 \mathrm{U} / \mathrm{l}))$, moderate renal impairment (creatinine $1.36 \mathrm{mg} / \mathrm{dl}(0.5-1.1 \mathrm{mg} / \mathrm{dl})$; estimated creatinine clearance $40 \mathrm{ml} / \mathrm{min}$ (Cockcroft-Gault formula with the adjusted body weight [22, 23]), and moderately elevated ALAT (186 U/l (<35 U/l)) (Figs. 1 and 2).

After obtaining written informed consent, genotype analyses were performed to determine the CYP3A5*3 (g6986A > G, rs776746) single nucleotide polymorphism (SNP), the ABCG2/BCRP SNP c.421C > A (rs2231142), and the $A B C B 1 / \mathrm{P}$-gp SNPs G2677 T/A (rs2032582) and C3435T (rs1045642), which all have been associated with functional impairment of the corresponding gene product $[20,24-26]$. Our patient was a CYP3A $5 * 3 / * 3$ non-expressor, a heterozygous carrier of the $A B C G 2$ c. $421 \mathrm{C} / \mathrm{A}$, and a homozygous carrier of $A B C B 1$ c.2677 T/T and $A B C B 1$ c.3435 T/T.

During the hospital stay, ischemic and hemorrhagic stroke was ruled out by brain imaging. The diagnostic work-up revealed a left-sided sciatic nerve lesion, proven by electrophysiological examinations, being the cause of her leg weakness. Additional findings encompassed an asymptomatic stenosis of the right internal carotid artery (60-70\%, NASCET criteria), urinary tract infection with E. coli ( $\geq 10^{5}$ colony-forming units $/ \mathrm{ml}$ ), and radiological signs of pneumonia accompanied by clinical infection signs and elevated laboratory inflammation markers (leukocytosis, C-reactive protein, and procalcitonin). Therefore, antibacterial therapy with metronidazole and ceftriaxone was started. After 10 days of hospitalization, the patient's renal function improved (creatinine 1.03 $\mathrm{mg} / \mathrm{dl}$ ) (Fig. 2) and she was transferred to a rehabilitation center. In January 2018, apixaban was restarted at the rehabilitation clinic after renal function had normalized (dosage: $5 \mathrm{mg}$ bid). Then, while taking apixaban, our patient suffered a duodenal/jejunal bleeding in May 2019. Transfusion of erythrocyte concentrates and interventional therapy was necessary and apixaban was 


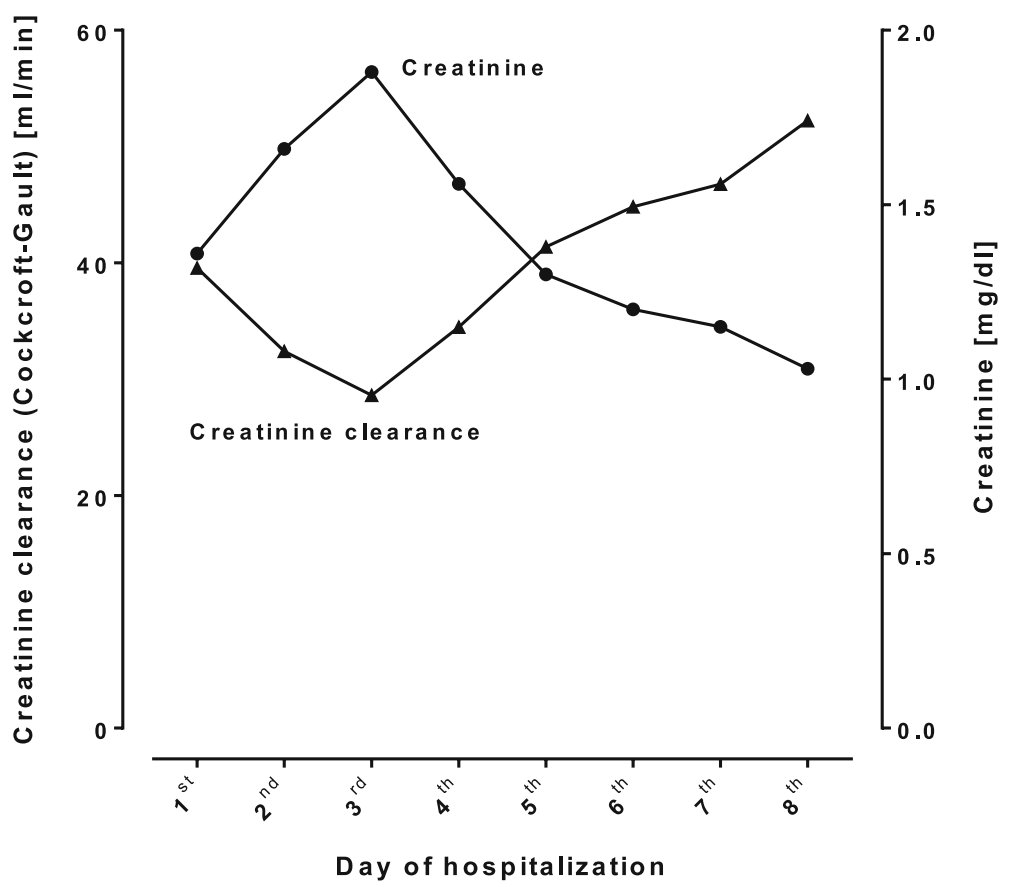

Fig. 1 Time course of renal function during the hospital stay. The creatinine clearance was calculated using the Cockcroft-Gault formula with the adjusted body weight

paused. In June 2019, she was diagnosed with acute myeloid leukemia (AML) and, due to pancytopenia, no anticoagulation was restarted until today (end of June 2019). Unfortunately, apixaban concentrations or specific anti-Xa activity were not assessed.

\section{Discussion}

Despite being regularly dosed with apixaban, our patient presented unexpectedly high plasma exposures and concurrent intense anticoagulation, which might be caused by a substantial impairment of apixaban elimination

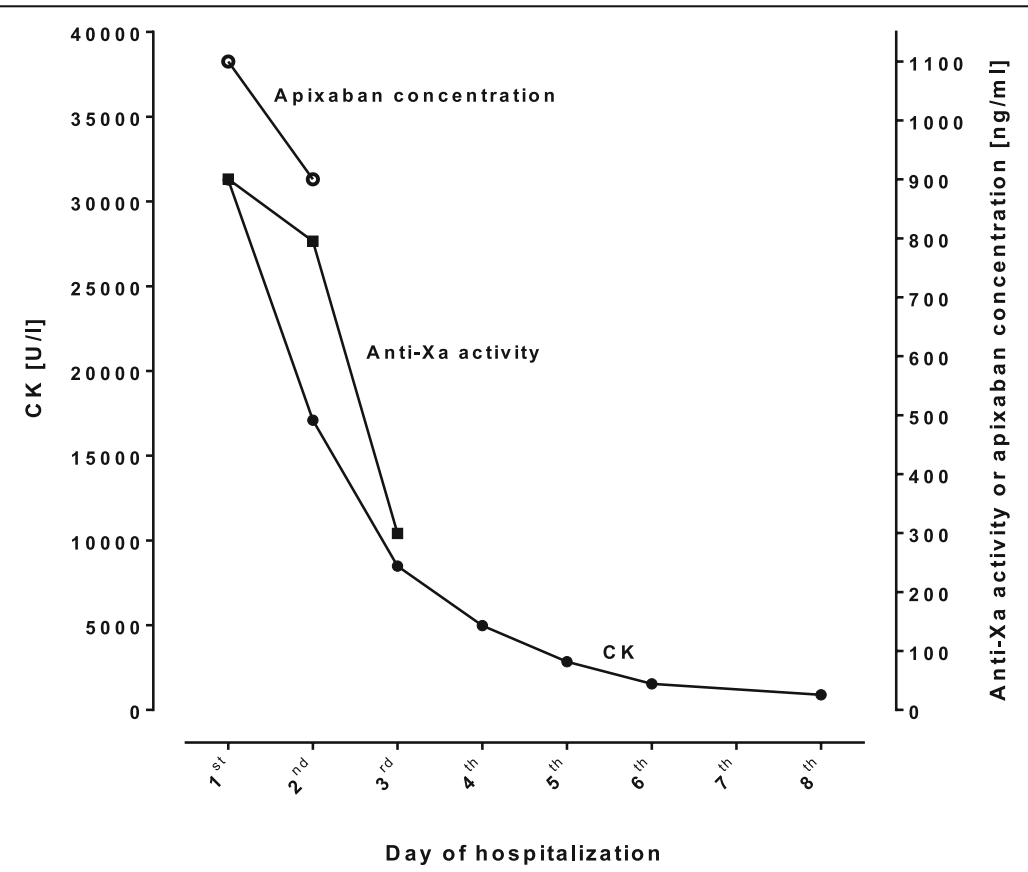

Fig. 2 Time course of creatine kinase, calibrated anti-factor Xa activity, and apixaban concentrations measured by ultra-performance liquid chromatography-tandem mass spectrometry 
pathways. Various factors can have led to high apixaban plasma concentrations and the long half-life (Fig. 3), but no currently known drug interaction was present. Renal impairment prolongs elimination half-life $[27,28]$ but the effect of renal impairment on apixaban concentrations is rather mild and our patient's renal function was only moderately impaired (clearance of $40 \mathrm{ml} / \mathrm{min}$ ). According to Chang and co-workers [27], in patients with a creatinine clearance of $40 \mathrm{ml} / \mathrm{min}$, the average increase in Cmax is $3.4 \%$ and in AUC 29\%, i.e. substantially smaller than observed in our patient. Hence, the observed excessively high apixaban concentrations and the very long half-life in our patient are suggestive to be caused by additional factors. Apixaban has a high solubility and low passive permeability [19] and its intestinal absorption of apixaban is modulated by active efflux transporters. Apixaban is a substrate of BCRP/ABCG2 [29] and also P-gp/ABCB1 [24, 29], which modulate apixaban absorption, tissue distribution, and elimination at least in rats [30]. Several BCRP and P-gp polymorphisms leading to reduced transporter activities have been described in Caucasians [31], which might modulate relevant pharmacokinetic pathways of apixaban. In addition, apixaban's major metabolites are mainly formed by the CYP3A enzyme family including the polymorphic CYP3A5 isozyme. In Japanese patients, BCRP and CYP3A5, but not P-gp polymorphisms were associated with higher apixaban trough concentrations $[20,26]$. With every impaired elimination pathway, the percentage contribution to drug clearance of the remaining individual pathways increases, indicating that concurrent impairment of several minor pathways could ultimately cause major exposure changes as shown for rivaroxaban [32].

Our patient was a CYP3A 5*3/*3 non-expressor, a heterozygous carrier of the $A B C G 2$ c.421C/A alleles, and a homozygous carrier of $A B C B 1$ c. $2677 \mathrm{~T} / \mathrm{T}$ and $A B C B 1$ c.3435 T/T. High apixaban exposures have already been reported in heterozygous and homozygous CYP3A5 non-expressors and in homozygous carriers of the deficient $A B C G 2$ c.421 A-allele, whereas heterozygous $A B C G 2$ c.421C/A carriers and $A B C B 1$ polymorphisms did not appear to influence apixaban pharmacokinetics [20, 26, 33]. However, thus far, apixaban pharmacokinetics of carriers of polymorphisms in all three pathways combined with moderate renal impairment has not been described. In sum, this genotype constellation could have led to a reduced clearance of apixaban. The clinical relevance of this finding remains unclear but such clearance changes might alter the risk/benefit relationship in affected patients because FXa plasma concentrations are directly linked to FXa inhibition [13] and efficacy and bleeding rates [17]. However, further studies to examine the genetic polymorphisms of apixaban metabolism and clinical outcome should be conducted particularly in patients with concurrent clearance impairment of other relevant drug elimination pathways such as the kidneys.

Our report has some limitations. First, the actually administered apixaban dose and time of drug intake are based on anamnestic information. Second, renal function was estimated using the Cockcroft-Gault equation, which overestimates renal function in patients with acute kidney injury. Thus, actual renal function was probably lower than the estimated value. However, the effects of renal impairment on apixaban pharmacokinetics are limited [27]. Finally, we assume that transient renal impairment was the only effect of rhabdomyolysis on apixaban pharmacokinetics; whether rhabdomyolysis can affect other apixaban clearance pathways is currently unknown.

\section{Conclusion}

We cared for a patient on oral anticoagulation with regular apixaban doses who had excessively high apixaban exposures and a substantially prolonged elimination half-life. The impaired clearance was most probably the result of moderate renal impairment combined with

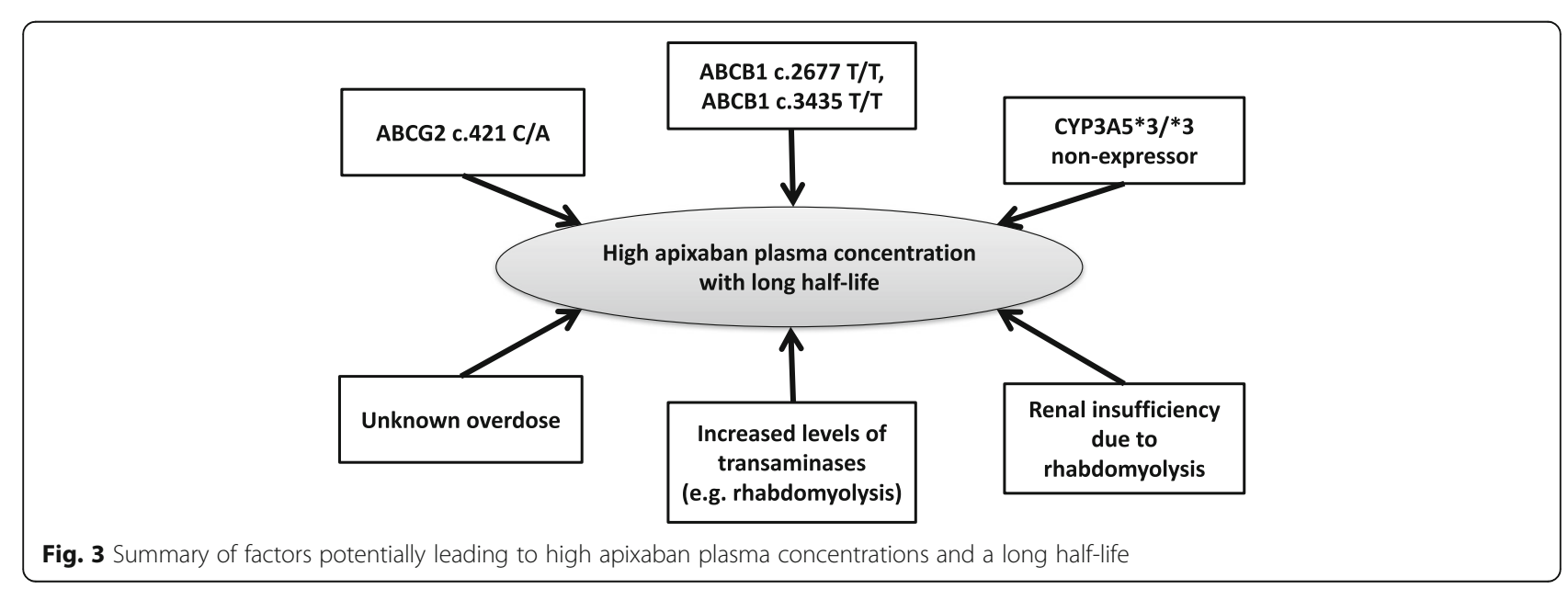


multiple functional polymorphisms of apixaban clearance pathways that are all partially involved in apixaban disposition and in sum may have caused substantial drug accumulation. Therefore, genotype analyses should be considered in patients with otherwise unexpected high plasma concentrations of apixaban.

\author{
Abbrevations \\ ALAT: Alanine aminotransferase; AML: Acute myeloid leukemia; \\ aPTT: Activated partial thromboplastin time; ASAT: Aspartate \\ aminotransferase; BCRP: Breast cancer resistance protein; CYP: Cytochrome \\ P450; DOAC: Direct oral anticoagulants; FXa: Factor Xa; INR: International \\ normalized ratio; NASCET: North American Symptomatic Carotid \\ Endarterectomy Trial; P-gp: P-glycoprotein; SNP: Single nucleotide \\ polymorphism
}

\section{Acknowledgements}

Not applicable.

\section{Authors' contributions}

$A H, W E H$, and TR analyzed all data and wrote the first draft of the manuscript. CGG performed genotype analyses. CD acquired clinical data of the patient. KIF and JB: performed quantitative analyses of DOAC plasma concentrations. JW: performed genotype analyses. DC: contributed to data analysis to the first draft of the manuscript. JP cared for the patient and established the clinical diagnosis. All authors critically reviewed and approved the final manuscript.

\section{Funding}

No funding.

\section{Availability of data and materials}

All the data supporting our findings are contained within the manuscript

\section{Ethics approval and consent to participate}

The Ethics Committee of the University Heidelberg approved the analysis of clinical data and of genetic polymorphisms (S-500/2016).

\section{Consent for publication}

Written informed consent was obtained from the patient for publication of her anonymized clinical details.

\section{Competing interests}

AH reports no competing interests.

CGG reports no competing interests.

$\mathrm{CD}$ reports no competing interests.

KIF reports no competing interests.

$\mathrm{JB}$ reports no competing interests.

JW reports no competing interests.

DC reports no competing interests.

JP received consulting honoraria, speakers' honoraria and travel support from BMS Pfizer, Boehringer Ingelheim, Akcea.

TR received consulting honoraria, speakers' honoraria and travel support from BMS Pfizer, Boehringer Ingelheim, Bayer HealthCare and Daiichi Sankyo, outside the submitted work.

WEH received consulting honoraria, speaker's honoraria and travel support from BMS, Boehringer Ingelheim, and Daiichi Sankyo and research support from Bayer, BMG, and Daichii-Sankyo outside the submitted work.

\section{Author details}

'Department of Clinical Pharmacology and Pharmacoepidemiology, Heidelberg University Hospital, Im Neuenheimer Feld 410, 69120 Heidelberg, Germany. ${ }^{2}$ Department of Neurology, Heidelberg University Hospital, Im Neuenheimer Feld 400, 69120 Heidelberg, Germany. ${ }^{3}$ Department of Vascular and Endovascular Surgery, University Hospital Heidelberg, Im Neuenheimer Feld 110, 69120 Heidelberg, Germany.
Received: 16 April 2019 Accepted: 23 August 2019

Published online: 29 August 2019

\section{References}

1. Wong PC, Pinto DJ, Zhang D. Preclinical discovery of apixaban, a direct and orally bioavailable factor Xa inhibitor. J Thromb Thrombolysis. 2011;31:478-92.

2. Wong PC, Crain EJ, Xin B, Wexler RR, Lam PY, Pinto DJ, et al. Apixaban, an oral, direct and highly selective factor Xa inhibitor: in vitro, antithrombotic and antihemostatic studies. J Thromb Haemost. 2008;6:820-9.

3. Pinto DJ, Orwat MJ, Koch S, Rossi KA, Alexander RS, Smallwood A, et al. Discovery of 1-(4-methoxyphenyl)-7-oxo-6-(4-(2-oxopiperidin-1-yl)phenyl) -4,5,6,7-tetrahydro-1H -pyrazolo[3,4-c]pyridine-3-carboxamide (apixaban, BMS-562247), a highly potent, selective, efficacious, and orally bioavailable inhibitor of blood coagulation factor Xa. J Med Chem. 2007;50:5339-56.

4. O'Donnell MJ, Eikelboom JW, Yusuf S, Diener HC, Hart RG, Smith EE, et al. Effect of apixaban on brain infarction and microbleeds: AVERROES-MRI assessment study. Am Heart J. 2016;178:145-50.

5. Peterson BE, Al-Khatib SM, Granger CB. Apixaban to prevent stroke in patients with atrial fibrillation: a review. Ther Adv Cardiovasc Dis. 2017;11:91-104

6. Granger CB, Alexander JH, McMurray JJ, Lopes RD, Hylek EM, Hanna M, et al. Apixaban versus warfarin in patients with atrial fibrillation. N Engl J Med. 2011;365:981-92

7. Ruff $C T$, Giugliano RP, Braunwald E, Hoffman EB, Deenadayalu N, Ezekowitz $M D$, et al. Comparison of the efficacy and safety of new oral anticoagulants with warfarin in patients with atrial fibrillation: a meta-analysis of randomised trials. Lancet. 2014:383:955-62.

8. Connolly SJ, Eikelboom J, Joyner C, Diener HC, Hart R, Golitsyn S, et al. Apixaban in patients with atrial fibrillation. N Engl J Med. 2011;364:806-17.

9. Diener HC, Eikelboom J, Connolly SJ, Joyner CD, Hart RG, Lip GY, et al. Apixaban versus aspirin in patients with atrial fibrillation and previous stroke or transient ischaemic attack: a predefined subgroup analysis from AVERROES, a randomised trial. Lancet Neurol. 2012;11:225-31.

10. Raghavan N, Frost CE, Yu Z, He K, Zhang H, Humphreys WG, et al. Apixaban metabolism and pharmacokinetics after oral administration to humans. Drug Metab Dispos. 2009:37:74-81.

11. Zhang D, He K, Raghavan N, Wang L, Mitroka J, Maxwell BD, et al. Comparative metabolism of 14C-labeled apixaban in mice, rats, rabbits, dogs, and humans. Drug Metab Dispos. 2009;37:1738-48.

12. Wang L, Zhang D, Raghavan N, Yao M, Ma L, Frost CE, et al. In vitro assessment of metabolic drug-drug interaction potential of apixaban through cytochrome P450 phenotyping, inhibition, and induction studies. Drug Metab Dispos. 2010;38:448-58.

13. Frost C, Nepal S, Wang J, Schuster A, Byon W, Boyd RA, et al. Safety, pharmacokinetics and pharmacodynamics of multiple oral doses of apixaban, a factor Xa inhibitor, in healthy subjects. Br J Clin Pharmacol. 2013:76:776-86

14. Sakaguchi T, Osanai $H$, Murase $Y$, Ishii $H$, Nakashima $Y$, Asano $H$, et al. Monitoring of anti-Xa activity and factors related to bleeding events: a study in Japanese patients with nonvalvular atrial fibrillation receiving rivaroxaban J Cardiol. 2017:70:244-9.

15. Reilly PA, Lehr T, Haertter S, Connolly SJ, Yusuf S, Eikelboom JW, et al. The effect of dabigatran plasma concentrations and patient characteristics on the frequency of ischemic stroke and major bleeding in atrial fibrillation patients: the RE-LY trial (randomized evaluation of long-term anticoagulation therapy). J Am Coll Cardiol. 2014;63:321-8.

16. Reilly PA, Connolly SJ, Yusuf S, Eikelboom JW, Ezekowitz MD, Wallentin L, et al. Reply: regarding the effect of dabigatran plasma concentrations. J Am Coll Cardiol. 2014;63:2885-6.

17. Ruff $C T$, Giugliano RP, Braunwald E, Morrow DA, Murphy SA, Kuder JF, et al. Association between edoxaban dose, concentration, anti-factor Xa activity, and outcomes: an analysis of data from the randomised, double-blind ENGAGE AF-TIMI 48 trial. Lancet. 2015;385:2288-95.

18. Foerster Kl, Huppertz A, Muller OJ, Rizos T, Tilemann L, Haefeli WE, et al. Simultaneous quantification of direct oral anticoagulants currently used in anticoagulation therapy. J Pharm Biomed Anal. 2018;148:238-44.

19. Eliquis: EPAR - Product Information; last updated 03/09/2018.

20. Ueshima S, Hira D, Fujii R, Kimura Y, Tomitsuka C, Yamane T, et al. Impact of $A B C B 1, A B C G 2$, and CYP3A5 polymorphisms on plasma trough 
concentrations of apixaban in Japanese patients with atrial fibrillation. Pharmacogenet Genomics. 2017;27:329-36.

21. Ofek F, Bar Chaim S, Kronenfeld N, Ziv-Baran T, Berkovitch M. International normalized ratio is significantly elevated with rivaroxaban and apixaban drug therapies: a retrospective study. Clin Ther. 2017;39:1003-10.

22. Winter MA, Guhr KN, Berg GM. Impact of various body weights and serum creatinine concentrations on the bias and accuracy of the Cockcroft-gault equation. Pharmacotherapy. 2012;32:604-12.

23. Bouquegneau A, Vidal-Petiot E, Moranne O, Mariat C, Boffa JJ, Vrtovsnik F, et al. Creatinine-based equations for the adjustment of drug dosage in an obese population. Br J Clin Pharmacol. 2016;81:349-61.

24. Zhang D, He K, Herbst JJ, Kolb J, Shou W, Wang L, et al. Characterization of efflux transporters involved in distribution and disposition of apixaban. Drug Metab Dispos. 2013;41:827-35.

25. Cullell N, Carrera C, Muino E, Torres N, Krupinski J, Fernandez-Cadenas I. Pharmacogenetic studies with oral anticoagulants. Genome-wide association studies in vitamin $\mathrm{K}$ antagonist and direct oral anticoagulants. Oncotarget. 2018;9:29238-58.

26. Ueshima S, Hira D, Kimura Y, Fujii R, Tomitsuka C, Yamane T, et al. Population pharmacokinetics and pharmacogenomics of apixaban in Japanese adult patients with atrial fibrillation. Br J Clin Pharmacol. 2018;84: 1301-12.

27. Chang M, Yu Z, Shenker A, Wang J, Pursley J, Byon W, et al. Effect of renal impairment on the pharmacokinetics, pharmacodynamics, and safety of apixaban. J Clin Pharmacol. 2016;56:637-45.

28. Mavrakanas TA, Samer CF, Nessim SJ, Frisch G, Lipman ML. Apixaban pharmacokinetics at steady state in hemodialysis patients. J Am Soc Nephrol. 2017;28:2241-8.

29. Hodin S, Basset T, Jacqueroux E, Delezay O, Clotagatide A, Perek N, et al. In vitro comparison of the role of P-glycoprotein and breast cancer resistance protein on direct oral anticoagulants disposition. Eur J Drug Metab Pharmacokinet. 2018:43:183-91.

30. Zhang D, Frost CE, He K, Rodrigues AD, Wang X, Wang L, et al. Investigating the enteroenteric recirculation of apixaban, a factor $X a$ inhibitor: administration of activated charcoal to bile duct-cannulated rats and dogs receiving an intravenous dose and use of drug transporter knockout rats. Drug Metab Dispos. 2013:41:906-15.

31. Bruhn O, Cascorbi I. Polymorphisms of the drug transporters ABCB1, ABCG2, $A B C C 2$ and $A B C C 3$ and their impact on drug bioavailability and clinical relevance. Expert Opin Drug Metab Toxicol. 2014;10:1337-54.

32. Moore KT, Vaidyanathan S, Natarajan J, Ariyawansa J, Haskell L, Turner KC. An open-label study to estimate the effect of steady-state erythromycin on the pharmacokinetics, pharmacodynamics, and safety of a single dose of rivaroxaban in subjects with renal impairment and normal renal function. $J$ Clin Pharmacol. 2014;54:1407-20.

33. Kryukov AV, Sychev DA, Andreev DA, Ryzhikova KA, Grishina EA, Ryabova AV, Loskutnikov MA, Smirnov W, Konova OD, Matsneva IA, Bochkov PO. Influence of $A B C B 1$ and CYP3A5 gene polymorphisms on pharmacokinetics of apixaban in patients with atrial fibrillation and acute stroke. Pharmgenomics Pers Med. 2018;11:43-9.

\section{Publisher's Note}

Springer Nature remains neutral with regard to jurisdictional claims in published maps and institutional affiliations.

\section{Ready to submit your research? Choose BMC and benefit from:}

- fast, convenient online submission

- thorough peer review by experienced researchers in your field

- rapid publication on acceptance

- support for research data, including large and complex data types

- gold Open Access which fosters wider collaboration and increased citations

- maximum visibility for your research: over $100 \mathrm{M}$ website views per year

At $\mathrm{BMC}$, research is always in progress.

Learn more biomedcentral.com/submissions 